\title{
Cognitive Improvement with Glutathione Supplement in Alzheimer's Disease: A Way Forward
}

\author{
Pravat K. Mandal ${ }^{\mathrm{a}, \mathrm{b}, *}$, Deepika Shukla ${ }^{\mathrm{a}}$, Manjari Tripathi ${ }^{\mathrm{c}}$ and Lars Ersland ${ }^{\mathrm{d}, \mathrm{e}, \mathrm{f}}$ \\ ${ }^{a}$ Neuroimaging and Neurospectroscopy Laboratory (NINS), National Brain Research Centre, Gurgaon, India \\ ${ }^{\mathrm{b}}$ Florey Institute of Neuroscience and Mental Health, University of Melbourne Medical school campus, \\ Melbourne, Australia \\ ${ }^{\mathrm{c}}$ Department of Neurology, All Indian Institute of Medical Science, New Delhi, India \\ ${ }^{\mathrm{d}}$ Department of Clinical Engineering, Haukeland University Hospital, Bergen, Norway \\ ${ }^{\mathrm{e}}$ Department of Biological and Medical Psychology, University of Bergen, Norway \\ ${ }^{\mathrm{f}}$ NORMENT Center of Excellence, Haukeland University Hospital, Norway
}

Accepted 10 January 2019

\begin{abstract}
Alzheimer's disease (AD) is a devastating neurodegenerative disorder affecting millions of people worldwide. The actual cause of AD is still unknown. Oxidative stress is believed to be important player in AD pathology. Glutathione (GSH) is a major antioxidant, and it is already known that GSH is depleted significantly in the hippocampal regions in mild cognitive impairment (MCI) and AD patients compared to healthy old subjects. Hence there is a serious discussion to improve the brain GSH level by supplementation. This editorial highlights the need for GSH supplementation for the cognitive enhancement in MCI and AD.
\end{abstract}

Alzheimer's disease (AD) is a progressive neurodegenerative disorder manifested by cognitive deterioration, progressive impairment of activities of daily living, and behavioral disturbances [1, 2]. Current conceptualization of $\mathrm{AD}$ presume that the neurodegenerative changes occur well before the clinical manifestations of the disease becomes apparent [3]. With progressive neuronal degeneration, formation of neurofibrillary tangles and neurotic plaques gradually increases. As a result, it sets a threshold for the initiation of clinical symptoms of

\footnotetext{
${ }^{*}$ Correspondence to: Dr. Pravat K. Mandal, Professor, National Brain Research Centre, Gurgaon, India. E-mails: pravat.mandal@ gmail.com and pravat@nbrc.ac.in; Honorary Professorial Fellow, Neurodegeneration Division, The Florey Institute of Neuroscience and Mental Health, University of Melbourne Campus, Victoria, Melbourne, Australia. E-mail: pravat.mandal@florey.edu.au.
}

\begin{abstract}
AD associated cognitive deficits which gradually worsen with time. The fundamental molecular etiology of neuronal loss resulting in cognitive decline in $\mathrm{AD}$ is still unknown. Although there are existing data to support amyloid [4], tau [5], oxidative stress $[6,7]$, membrane alternation $[8]$, and soluble oligomeric amyloid- $\beta(\mathrm{A} \beta)[9,10]$ hypotheses, research in the clinical setting has indicated that oxidative stress plays an important role in the pathogenesis of $\mathrm{AD}$ [11-14]. Oxidative stress is a general term used to describe the steady state level of oxidative damage in a cell, tissue, or organ, caused by the reactive oxygen species (ROS). ROS are chemically unstable and highly reactive, but their levels are kept relatively low by antioxidants (e.g., GSH, vitamin $\mathrm{E} \& \mathrm{C}$, etc.). These facts underline the importance of an effective brain antioxidant system during the
\end{abstract}


life span. Antioxidant strategies for AD include systematic treatment with vitamin $\mathrm{C}$ and $\mathrm{E}[15,16]$, but results indicated that there were no significant clinical protective effects of vitamin $\mathrm{E}$ and $\mathrm{C}$ in dementia $[17,18]$.

Glutathione is a potent antioxidant and detoxifying agent that is produced de novo in the cytoplasm of every cell of the human body. The significant amount of GSH in the human brain are used for radical scavenging and balancing ROS. The intracellular brain antioxidant GSH interconverts into reduced GSH and GSSG, maintaining the ratio in most cells around 500:1 $[19,20]$. Transgenic mice (which develop $A \beta$ plaques throughout the cortex) show a significant decrease in GSH levels compared to wild type mice [21]. Studies in AD patients have shown that GSH metabolism is altered and regulated differently in male and female patients [22].

A recent study has shown that the depletion of GSH level in MCI and AD patients in the hippocampal regions is directly correlated with executive function using the Trail Making (B-A) test score [12]. Another study has demonstrated that intranasal administration of GSH elevates brain GSH levels in Parkinson's disease (PD) patients [23]. However, to the best of our knowledge, no clinical trial has evaluated similar effects of GSH supplementation and its subsequent bioavailability in the brain tissue. There is no GSH trial available for AD patients, where GSH level in the brain were monitored non-invasively as well as behavioral studies in MCI patients. Hence, this editorial sensitizes the importance of GSH supplementation involving MCI patients to improve cognitive performance using peripheral supplements.

\section{GLUTATHIONE DETECTION IN PLASMA AND AUTOPSY STUDIES}

GSH is a tripeptide consisting of the three amino acids namely: glutamate, cysteine, and glycine. GSH exists in two forms: reduced (GSH) and oxidized (GSSG) forms. The reduced form of GSH has two predominant conformations (extended and closed) as shown by a recently conducted multi-center in vivo MRS studies [24, 25]. GSH is reported to decrease with age and ageassociated disorders in animal model studies [26] as well as human brain autopsy studies [27]. The GSH concentrations in the normal healthy brain were reported to be $1.18 \pm 0.09 \mathrm{mM}$ and $0.83 \pm$ $0.03 \mathrm{mM}$, respectively, from the white and the gray matters of parietal cortex regions $(\mathrm{N}=5)$ [28]. Another autopsy study has reported that GSH level decrease in the hippocampus $(\mathrm{N}=25)$ and frontal cortex $(\mathrm{N}=31)$ with age [27]. A clinical study reported significant decrease in plasma GSH levels in MCI $(\mathrm{N}=34)$ and $\mathrm{AD}(\mathrm{N}=45)$ compared to age-matched control subjects $(\mathrm{N}=28)$ [29]. The glutathione peroxidase (GPx) in plasma were measured in MCI $(\mathrm{N}=25)$, AD patients $(\mathrm{N}=63)$ and controls subjects $(\mathrm{N}=53)$. Furthermore, the activities of antioxidants in plasma were depleted in MCI and AD patients as compared to controls [30]. Autopsy studies involving $\mathrm{AD}, \mathrm{PD}$, and dementia with Lewy bodies (DLB) have reported that the GSH level in the cingulated cortex region of $\mathrm{AD}$ patients is reduced by $49 \%$ as compared to age-matched control subjects. Such a specific change of GSH depletion is not found in PD and DLB patients. Another postmortem study in MCI, mild and severe AD brains has revealed depleted GSH levels in both, mitochondrial, and synaptosomal fractions from frontal cortices, as compared to controls [31].

\section{DETECTION OF GSH in vivo HEALTHY AND MCI/AD PATIENTS USING MR SPECTROSCOPY}

Autopsy [27] as well as neuroimaging [13] studies have reported close association of the GSH distribution in human brain with gender, age, disease condition, and anatomical area. Glutathione can be detected in vivo selectively by the application of specialized pulse sequences [13, 32, 33]. GSH is distributed in various neuroanatomical regions of healthy subjects as well as patients with MCI and $\mathrm{AD}$ as reported using in vivo MRS studies [13]. Accordingly, healthy young brains showed higher GSH content and a specific GSH distribution pattern in various brain regions. The mean GSH content and distribution varied between male and female healthy subjects when compared between left frontal cortex (LFC) and right frontal cortex (RFC) [13]. It was reported that the reduction of GSH in both hippocampus and frontal cortices correlated $(p<0.001)$ with decline in cognitive functions [12]. Receiver operator characteristics analyses showed that hippocampal GSH depletion distinguish between MCI and elderly healthy controls with $87.5 \%$ sensitivity, $100 \%$ specificity, whereas cortical region GSH level differentiates MCI and AD with $91.7 \%$ sensitivity, $100 \%$ specificity [12]. The significant reduction in GSH selectively in the brain regions (frontal cortex and 
hippocampus) affected by AD pathology, but not in the cerebellum of AD patients [12]. The autopsy studies indicated significant depletion of GSH level in cingulated cortex regions by $49 \%$ in AD subject. Moreover, this GSH depletion trend is found in MCI, and $\mathrm{AD}$ subjects from in vivo $\mathrm{MR}$ spectroscopic studies of frontal cortices and hippocampal regions $[12,13]$.

In another MRS study involving MCI subjects, it was found that GSH level increases with MCI compared to elderly control [34]. This increase in GSH level was explained as an early compensatory or neuroprotective response [34]. However, in the same study, the GSH peak was identified using PRESS pulse sequence in a $3 \mathrm{~T}$ scanner where GSH peak appeared in close proximity of high intense choline peak. The probable anomaly of these results is due to the use of a PRESS sequence for detection of GSH. With this technique the GSH signal will be partly overlapped by intense signals arising from choline and creatine, thus complicating the accurate measurement of GSH. The MEGA-PRESS pulse sequence, on the other hand, is a very selective and confirmatory method to detect the GSH peaks. Hence, in any clinical trial involving GSH measurement, MRS with MEGA-PRESS should be the method of choice for AD clinical study with GSH [23].

\section{VARIOUS TRIALS WITH GSH AND OTHER ANTIOXIDANTS}

There are various clinical trials involving GSH to investigate GSH transportation across the intestinal epithelium [35], therapeutic effects of oral administration of glutathione in patients with non-alcoholic fatty liver disease [36], effect of oral GSH supplementation on changes in erythrocyte GSH level [37, 38]. The effect of GSH on anti-aging features (wrinkles in the skin) was also investigated [39, 40].

It was reported that GSH can be transported across the intestinal epithelium in an orally administered GSH in animal model study and the initial uptake of GSH into cells is reported as a rapid process [35]. The ingested GSH has potent nutraceutical benefits for human health to improve oxidative stress and defense in human [35]. The therapeutic effects of oral administration of GSH in patients with non-alcoholic fatty liver disease in open label, single arm, multi-center trial [36] indicated a significant decrease in alanine aminotransferase level as well as triglycerides, nonesterified fatty acids, and ferritin levels [36]. To determine the effect of oral GSH supplementation on ery- throcyte GSH concentrations, including total reduced GSH, oxidized glutathione (GSSG), and their ratio in a randomized, double-blind, placebo-controlled clinical trial for 4 weeks on 40 healthy volunteers were conducted. Changes in erythrocyte GSH concentrations, including total GSH, oxidized glutathione (GSSG), and GSH: GSSG ratios were monitored. No significant changes in GSH concentrations in erythrocyte were observed [37]. In a long-term study, the effect of oral GSH supplementation on body stores of GSH in healthy adults, randomized, doubleblinded, placebo-controlled trial GSH supplement for 6 months on 54 adults was conducted. GSH levels in blood increased after 1, 3, and 6 months versus baseline. At 6 months, mean GSH levels increased $30-35 \%$ in erythrocytes, plasma, and lymphocytes and $260 \%$ in buccal cells in the high-dose group. GSH levels increased $17 \%$ and $29 \%$ in blood and erythrocytes respectively, in the low-dose group. Natural killer cytotoxicity increased twofold in the high-dose group versus placebo [38]. This clearly demonstrates that study duration for oral GSH supplementation plays an important role for study outcome.

The orally administered GSH (500 mg per day for 4 weeks, on 60 healthy medical students) affects the skin melanin index, when compared with placebo in a randomized, double-blind, two-arm, placebocontrolled study. It was observed that melanin indices decreased consistently at two sites. Both GSH and placebo were very well tolerated. Oral GSH administration resulted in lightening of skin color [40]. In another similar type of study, to evaluate the influences of both GSH and oxidized form (GSSG) at doses lower than $500 \mathrm{mg} / \mathrm{d}$, on improving skin properties, a randomized, double-blind, placebo-controlled, study was conducted [39]. Oral GSH was administered for 12 weeks in 60 healthy volunteers, and skin features including melanin index, wrinkles, and other relevant biophysical properties were measured. Blood samples were collected for safety monitoring. GSH showed a significant reduction in wrinkles compared with those taking placebo. A tendency toward increased skin elasticity was observed in GSH compared with placebo. There were no serious adverse effects throughout the study [39].

A phase IIb randomized double blind, placebo controlled trial on 45 PD patients (Hoehn \& Yahr stages 1-3) monitored the symptomatic relief effect of intranasal GSH supplement by administering $200 \mathrm{mg}$ GSH thrice daily for three months. The subjects were observed over a one-month washout period. All cohorts of this study, including placebo showed 
improvement during the intervention regime. However, as this study aimed at evaluating an appropriate trial design, conclusions regarding the superiority of GSH over placebo were not drawn [23].

To compare bioavailability, the effect on oxidative stress markers and the safety of a new sublingual form of GSH was studied with two commonly used dietary supplements: N-acetylcysteine (NAC) and oral GSH. In this randomized crossover study, sublingual GSH, oral GSH and NAC were administered for 3 weeks in 20 normal volunteers. Bioavailability, antioxidant efficacy, tolerance, reduced thiols, vitamin E, lipid status and adverse effects were monitored [41]. Significant superiority of a new sublingual form of GSH compared to both oral GSH and NAC, were observed. All the dosage forms were well tolerated and no adverse events were reported [41]. A nutraceutical formulation containing $\mathrm{N}$-acetylcysteine among other compounds has shown some pro-cognitive benefits in $\mathrm{AD}$ and older adults, but the impact of NAC alone is less robust [42].

\section{FUTURE TRIAL INVOLVING GSH FOR COGNITIVE IMPROVEMENT IN MCI AND AD}

To date, all GSH trials conducted addressed the bioavailability, tolerance level, dose dependence, and duration of the oral supplementation. Existing literature clearly indicates that oral supplementation for $500 \mathrm{mg} /$ day indeed enters the blood stream and has enhanced the GSH level in the erythrocyte. To the best of our knowledge, there is no non-invasive brain imaging based study/trial available in the clinical trial database or other cognitive performance improvement studies. Therefore, there is an urgent need for the study on GSH supplementation involving MCI and AD patients. Further more, MRS measurement of GSH in the hippocampus needs to be monitored on those participants at various time points. The neuropsychological battery of tests at various time points for cognitive profile evaluation should be part of the upcoming clinical study. Finally, the GSH level in the hippocampus region and its correlation with the cognitive score will be a great measure for the identification of the impact of GSH supplementation both for MCI and AD compared to participants treated with placebo.

\section{ACKNOWLEDGMENTS}

Dr. Pravat Mandal (Principal Investigator) thanks the Department of Biotechnology, Ministry of Science and Technology, Government of India for funding this project (Grant no BT/Indo-Aus/10/31/ 2016/PKM) and acknowledges partial funding support from the Ministry of Information Technology, Govt. of India (DeitY/R\&D/TDC/13(5)/2013 dated 20/12/2013). Financial support in the form of TATA INNOVATION AWARD (Award No.BT/HRD/01/ 05/2015) from the ministry of Science and Technology, Government of India is appreciated. Thanks to Ms. Divya Dwivedi, Project Assistant in the NINS lab (NBRC), for participating in literature search and Mr. Ritwick Mishra (Clinical Coordinator at NINS lab) for proof reading.

Authors' disclosures available online (https:// www.j-alz.com/manuscript-disclosures/18-1054r2).

\section{REFERENCES}

[1] Cummings JL (2004) Drug therapy - Alzheimer's disease. N Engl J Med 351, 56-67.

[2] Braak E, Griffing K, Arai K, Braak H (1999) Neuropathology of Alzheimer's disease: What is new since A. Alzheimer. Eur Arch Psychiatry Clin Neurosci 249, 14-22.

[3] Nestor PJ, Scheltens P, Hodges JR (2004) Advances in the early detection of Alzheimer's disease. Nat Rev Neurosci 10 Suppl, S34-S41.

[4] Hardy J, Selkoe DJ (2002) Medicine - The amyloid hypothesis of Alzheimer's disease: Progress and problems on the road to therapeutics. Science 297, 353-356.

[5] Trojanowski JQ, Lee VMY (2002) The role of tau in Alzheimer's disease. Med Clin North Am 86, 615-627.

[6] Perry G, Nunomura A, Hirai K, Zhu XW, Perez M, Avila J, Castellani RJ, Atwood CS, Aliev G, Sayre LM, Takeda A, Smith MA (2002) Is oxidative damage the fundamental pathogenic mechanism of Alzheimer's and other neurodegenerative diseases? Free Radic Biol Med 33, 1475-1479.

[7] Casetta I, Govoni V, Granieri E (2005) Oxidative stress, antioxidants and neurodegenerative diseases. Curr Pharm Design 11, 2033-2052.

[8] Pettegrew JW (1989) Molecular insights into Alzheimer's disease. Ann N Y Acad Sci 568, 5-28.

[9] Mandal PK, Pettegrew JW (2004) Alzheimer's disease: Soluble oligomeric A beta(1-40) peptide in membrane mimic environment from solution NMR and circular dichroism studies. Neurochem Res 29, 2267-2272.

[10] Kayed R, Head E, Thompson JL, McIntire TM, Milton SC, Cotman CW, Glabe CG (2003) Common structure of soluble amyloid oligomers implies common mechanism of pathogenesis. Science 300, 486-489.

[11] Barnham KJ, Masters CL, Bush AI (2004) Neurodegenerative diseases and oxidative stress. Nat Rev Drug Discov 3, 205-214.

[12] Mandal PK, Saharan S, Tripathi M, Murari G (2015) Brain glutathione levels-a novel biomarker for mild cognitive 
impairment and Alzheimer's disease. Biol Psychiatry 78, 702-710.

[13] Mandal PK, Tripathi M, Sugunan S (2012) Brain oxidative stress: Detection and mapping of anti-oxidant marker 'Glutathione' in different brain regions of healthy male/female, $\mathrm{MCI}$ and Alzheimer patients using non-invasive magnetic resonance spectroscopy. Biochem Biophys Res Commun 417, 43-48.

[14] Butterfield DA, Pocernich CB, Drake J (2002) Elevated glutathione as a therapeutic strategy in Alzheimer's disease. Drug Dev Res 56, 428-437.

[15] Boothby LA, Doering PL (2005) Vitamin C and vitamin E for Alzheimer's disease. Ann Pharmacotherapy 39, 20732080.

[16] Kontush K, Schekatolina S (2004) Vitamin E in neurodegenerative disorders: Alzheimer's disease. Ann N Y Acad Sci 1031, 249-262.

[17] Kryscio RJ, Abner EL, Caban-Holt A, Lovell M, Goodman P, Darke AK, Yee M, Crowley J, Schmitt FA (2017) Association of antioxidant supplement use and dementia in the prevention of Alzheimer's Disease by Vitamin E and Selenium Trial (PREADViSE). JAMA Neurol 74, 567-573.

[18] Masaki KH, Losonczy KG, Izmirlian G, Foley DJ, Ross GW, Petrovitch H, Havlik R, White LR (2000) Association of vitamin $\mathrm{E}$ and $\mathrm{C}$ supplement use with cognitive function and dementia in elderly men. Neurology 54, 1265-1272.

[19] Dringen R, Hirrlinger J (2003) Glutathione pathways in the brain. Biol Chem 384, 505-516.

[20] Stryer L (1988) Glutathione serves as a sulfhydryl buffer and amino acid transporter. In Biochemistry, W.H. Freeman, New York, pp. 489-492.

[21] Dedeoglu A, Choi JK, Cormier K, Kowall NW, Jenkins BG (2004) Magnetic resonance spectroscopic analysis of Alzheimer's disease mouse brain that express mutant human APP shows altered neurochemical profile. Brain Res 1012, 60-65.

[22] Liu HL, Harrell LE, Shenvi S, Hagen T, Liu RM (2005) Gender differences in glutathione metabolism in Alzheimer's disease. J Neurosci Res 79, 861-867.

[23] Mischley LK, Lau RC, Shankland EG, Wilbur TK, PU, Padowski JM (2017) Phase IIb study of intranasal glutathione in Parkinson's disease. J Parkinson Dis 7, 289-299.

[24] Shukla D, Mandal PK, Ersland L, Renate Gruner E, Tripathi M, Raghunathan P, Sharma A, Chaithya GR, Punjabi K, Splaine C (2018) A multi-center human brain glutathione conformation study from magnetic resonance spectroscopy. $J$ Alzheimers Dis 66, 517-532.

[25] Mandal PK, Shukla D (2018) Brain metabolic, structural, and behavioral pattern learning for early predictive diagnosis of Alzheimer's disease. J Alzheimers Dis 63, 935-939.

[26] Liu H, Wang H, Shenvi S, Hagen TM, Liu RM (2004) Glutathione metabolism during aging and in Alzheimer disease. Ann N Y Acad Sci 1019, 346-349.

[27] Venkateshappa C, Harish G, Mahadevan A, Srinivas Bharath MM, Shankar SK (2012) Elevated oxidative stress and decreased antioxidant function in the human hippocampus and frontal cortex with increasing age: Implications for neurodegeneration in Alzheimer's disease. Neurochem Res 37, 1601-1614.
[28] Slivka A, Spina MB, Cohen G (1987) Reduced and oxidized glutathione in human and monkey brain. Neurosci Lett 74, 112-118.

[29] Bermejo P, Martin-Aragon S, Benedi J, Susin C, Felici E, Gil P, Ribera JM, Villar AM (2008) Peripheral levels of glutathione and protein oxidation as markers in the development of Alzheimer's disease from mild cognitive impairment. Free Radic Res 42, 162-170.

[30] Rinaldi P, Polidori MC, Metastasio A, Mariani E, Mattioli R, Cherubini A, Catani M, Cecchetti R, Senin U, Mecocci $\mathrm{P}$ (2003) Plasma antioxidants are similarly depleted in mild cognitive impairment and in Alzheimer's disease. Neurobiol Aging 24, 915-919.

[31] Ansari MA, Scheff SW (2010) Oxidative stress in the progression of Alzheimer disease in the frontal cortex. J Neuropathol Exp Neurol 69, 155-167.

[32] Trabesinger AH, Weber OM, Duc CO, Boesiger P (1999) Detection of glutathione in the human brain in vivo by means of double quantum coherence filtering. Magn Reson Med 42, 283-289.

[33] Terpstra M, Henry PG, Gruetter R (2003) Measurement of reduced glutathione (GSH) in human brain using LC model analysis of difference-edited spectra. Magn Reson Med 50, 19-23.

[34] Duffy SL, Lagopoulos J, Hickie IB, Diamond K, Graeber MB, Lewis SJ, Naismith SL (2014) Glutathione relates to neuropsychological functioning in mild cognitive impairment. Alzheimers Dement 10, 67-75.

[35] Kovacs-Nolan J, Rupa P, Matsui T, Tanaka M, Konishi T, Sauchi Y, Sato K, Ono S, Mine Y (2014) In vitro and ex vivo uptake of glutathione (GSH) across the intestinal epithelium and fate of oral GSH after in vivo supplementation. J Agric Food Chem 62, 9499-9506.

[36] Honda Y, Kessoku T, Sumida Y, Kobayashi T, Kato T, Ogawa Y, Tomeno W, Imajo K, Fujita K, Yoneda M, Kataoka K, Taguri M, Yamanaka T, Seko Y, Tanaka S, Saito S, Ono M, Oeda S, Eguchi Y, Aoi W, Sato K, Itoh Y, Nakajima A (2017) Efficacy of glutathione for the treatment of nonalcoholic fatty liver disease: An open-label, single-arm, multicenter, pilot study. BMC Gastroenterol 17, 96.

[37] Allen J, Bradley RD (2011) Effects of oral glutathione supplementation on systemic oxidative stress biomarkers in human volunteers. J Altern Complement Med 17, 827-833.

[38] Richie JP Jr, Nichenametla S, Neidig W, Calcagnotto A, Haley JS, Schell TD, Muscat JE (2015) Randomized controlled trial of oral glutathione supplementation on body stores of glutathione. Eur J Nutr 54, 251-263.

[39] Weschawalit S, Thongthip S, Phutrakool P, Asawanonda P (2017) Glutathione and its antiaging and antimelanogenic effects. Clin Cosmet Investig Dermatol 10, 147-153.

[40] Arjinpathana N, Asawanonda P (2012) Glutathione as an oral whitening agent: A randomized, double-blind, placebocontrolled study. J Dermatolog Treat 23, 97-102.

[41] Schmitt B, Vicenzi M, Garrel C, Denis FM (2015) Effects of $\mathrm{N}$-acetylcysteine, oral glutathione (GSH) and a novel sublingual form of GSH on oxidative stress markers: A comparative crossover study. Redox Biol 6, 198-205.

[42] Hara Y, McKeehan N, Dacks PA, Fillit HM (2017) Evaluation of the neuroprotective potential of $\mathrm{N}$-acetylcysteine for prevention and treatment of cognitive aging and dementia. J Prev Alzheimers Dis 4, 201-206. 